\title{
Covid-19 Related Anxiety and Coping Strategies among Urban Working and Non-working Mothers in North India
}

\author{
Prachi Bisht* and Deepika Vig \\ HD\&FS, PAU, Ludhiana, India \\ *Corresponding author
}

\section{Ke y w o r d s}

Anxiety and coping strategies, Urban

Working and Nonworking mothers

Article Info

Accepted:

17 June 2020

Available Online:

10 July 2020

\begin{abstract}
A B S T R A C T
There are plethoras of anecdotal evidences that indicate that covid-19 pandemic has induced anxiety among people across the globe. Due to various social, cultural and economic factors, the present condition has worsen the situation of already vulnerable group of our society i.e. the women. Therefore the present study intends to explore that how the pandemic has impacted the mental health of working and non-working women. The study was conducted on total 300 married urban women (150 working and 150 non working) during phase 1 of lockdown, data was collected through online survey applying a self structured covid related anxiety scale. The results showed that there are non-significant differences in Anxiety and statistically significant difference $(\mathrm{t}=4.8)$ in Coping strategies between working and non-working women. Working women had high mean score for coping strategy proving that working women were mindfully managing the adverse situation of pandemic as compared to non-working women.
\end{abstract}

\section{Introduction}

Anxiety is feeling of unrealistic fear, worry, and uneasiness, usually generalized and unfocussed. It is characterized by psychological symptoms such as insomnia, lack of appetite and lack of concentration concentrating and further manifests into somatic or physical symptoms such as racing heartbeat, sweating and trembling (Rajni 2016). It is body's response to the stressors present around us however if it is persistent then it becomes a cause of concern. The onset of pandemic has instill continuous fear and anxiety in most individuals and people react to the present stressor i.e. covid 19 with different manner or coping strategies depending upon their resilience, ability to deal with stress, support system around them etc.

The psychological distress and way of handling it during any pandemic situation could be different for different groups of population e.g. mental disorders can affect women and men differently. Some disorders are more common in women such as depression and anxiety (National Institute of mental health, 2019) because of the different 
roles and responsibilities posed upon them by the society lockdowns and self-quarantine measures across the world have aggravated women's workload as care giving tasks.

Women are considered a vulnerable group of any society but ironically they also have responsibility to take care of the other two vulnerable groups i.e. children and elderly of the family. In the present global health crisis the challenge for women is not just prevention and care from the infection but also taking care of the family as a whole, engaging the children in productive activities, keeping herself mentally balanced, doing household chores and maintain house budget etc. Many women are working at home and also working from home bearing the double challenge of being efficient in professional as well as household front .The virus outbreak has brought many challenges in front of them. The fear of concern can be amplified by preexisting anxiety and depressive disorder (Taha et al., 2014). Individuals experience a general distress that results in tendency to do in negative interpretative biases attributing to their health (Hillick and Margret, 1998). Persistent worrying leads to an avoidance reaction and dependence on culturally promoted illness avoidance practices (Chang et al., 2004).

The challenges posed upon working and nonworking mothers have always been different. Iquabal et al., (2004) found that engagement of non -working women in less number of roles may also be a contributory factor towards high anxiety in non-working women. The study concluded that non-working women suffer more from anxiety as compared to working women. Kamu (1992) point out that importance of economic freedom, social status and other similar attributes in as much as the working women feels more secured as compared to their non-working counterparts whereas Cooper (1981) reported that working women were more under stress than nonworking married women. Findings indicated that working married women who are engaged in multiple roles had to face sever stressful situations at work sometimes serve as to put a woman into an unhappy .However in context to covid 19, there is no evidence based study that compares the anxiety levels and the coping strategies followed by the working and non-working mothers and becomes the urgent need to address the issues of mental illness being prominently visible in the society during the present prevalent pandemic.

The main objectives of this study include to assess and compare the covid related anxiety and coping strategy among working and nonworking married urban mothers.

\section{Materials and Methods}

\section{Sample and location}

The present study was conducted urban women belonging to various states of north India (predominantly from Punjab, Uttarakhand, Delhi, Uttar Pradesh, Himanchal Pradesh and Haryana). The study was carried out in the first phase of lockdown i.e. between the month of April 2020-May2020. The total sample comprised of 300 married urban women in the reproductive age group of 1848 years, belonging to middle socio economic status, out of which 150 belonged to working class and 150 women belonged to nonworking class selected through random purposive sampling.

\section{Tools}

A self structured online questionnaire was developed to assess the Covid related anxiety and coping strategies adapted from Hamilton Anxiety Scale (1998).The Scale has three dimensions assessing i.e. psychological 
symptoms of anxiety, somatic symptoms of anxiety, and copying strategies. Psychological symptoms and somatic symptoms scores were combined to assess the overall Anxiety levels to categorize the respondents into four levels i.e. No Anxiety, Mild Anxiety, Moderate anxiety and Severe Anxiety. To assess copying strategies, the scale had 10 sets of items the items related to copying strategies were based on utilization of extra time, indulgence in binge eating and drinking, screen time, hobby, physical activity, socialization etc. to categorize the respondents into three levels i.e. highly mindful coping strategy, Moderate mindful coping strategy and Low mindful coping strategy.

Socio demographic data was collected through a self structured questionnaire.

\section{Data collection}

The items of the scale was fed into Google form and distributed widely through social media, email and whatsapp messages, the respondents submitted the responses online and were received in email at the end of the researcher.

\section{Statistical analysis}

The data was analyzed using statistical techniques like frequency, percentage, mean, standard deviation and students-T test.

\section{Results and Discussion}

As described in the table 1, dimensions of anxiety i.e. Psychological symptoms and Somatic symptoms and overall anxiety are being compared between working and nonworking mothers. The table also compares the coping strategies between working and nonworking mothers. The results indicates that the mean scores of psychological symptoms of anxiety, somatic and overall anxiety of working women are slightly higher as compared to the mean scores of the nonworking mothers, however $\mathrm{t}$ value shows that the difference is insignificant. This Indicate that there is no significant difference in the covid related anxiety between both the counterparts but slightly higher among working mothers. The table further shows the mean scores of coping strategies and it was found that working women scored higher mean scores than their counterpart and $\mathrm{t}$ value $(\mathrm{t}=4.8 ; \mathrm{p}<0.01)$ indicate a significant difference between the two groups. This shall highlight the fact that working women are dealing with the covid-19 stress in a highly mindful manner than non-working women.

The above finding is contradictory with the finding of Neeraj Panwar (2011) who found that working women feels low anxiety comparison to non-working women which was conducted during normal (non-covid) phase, therefore the elevation in anxiety levels proves that covid has induced anxiety among working women because of the dual responsibilities posed upon them, more care giving tasks and work from home all are contributing factors that made the lockdown challenging for them.

\section{Distribution of working and non-working mothers on various levels of anxiety}

Table 2 indicate the frequency and percentage distribution of working and non working mothers on various levels of anxiety i.e. No anxiety, mild anxiety, moderate anxiety and severe anxiety. It was found that majority of the total respondents(62.2\%)as well as both the groups (58\% and 67\%) showed mild covid related anxiety followed by no anxiety $(19 \%)$, moderate anxiety(15.6\%) and just $2.66 \%$ reported severe anxiety. Among working women equal number of respondents (19\%) reported no anxiety and moderate anxiety. 
The possible reason of such trend could be attributed to time when the study was undertaken. Since the study was conducted in the initial days of lockdown(April), the severity of the disease in terms of number of positive cases and number of death in India were few as compared to what it is today. It took time for people to judge the situation and the threat of covid. The interpretation drawn from the above analysis is that during initial phase of lockdown1 the people started developing covid fear that came out as mild anxiety however significant number of moderate and few severe anxiety were reported as well. It was also found that in comparison to non-working mothers, working mothers reported 3\% higher cases of sever anxiety.

Table.1 Differences (Mean scores \pm SD) in Anxiety and Coping strategies among working and non-working mothers

\begin{tabular}{|c|c|c|c|c|c|}
\hline & \multicolumn{2}{|c|}{ Working mothers } & \multicolumn{2}{|c|}{ Non-working mothers } & \multirow[t]{2}{*}{ T value } \\
\hline & $\mathrm{f}$ & $\%$ age & $\mathrm{f}$ & \%age & \\
\hline $\begin{array}{l}\text { Psychological } \\
\text { Symptoms of } \\
\text { anxiety }\end{array}$ & 23.82 & 6.11 & 22.97 & 5.9 & 0.214 \\
\hline $\begin{array}{l}\text { Somatic symptoms } \\
\text { of Anxiety }\end{array}$ & 6.92 & 1.73 & 6.81 & 1.49 & 0.721 \\
\hline Overall Anxiety & 30.28 & 6.97 & 29.29 & 6.58 & 0.233 \\
\hline Coping Strategies & 17.76 & 3.5 & 14 & 4.51 & $4.8 * *$ \\
\hline
\end{tabular}

*P $\quad<.05 \%,{ }^{* *} \mathrm{P}<0.01 \%$ (Table 1$)$

Table.2 Levels of Anxiety in working and non working mothers

\begin{tabular}{|c|c|c|c|c|c|c|}
\hline \multirow{2}{*}{$\begin{array}{l}\text { Levels of } \\
\text { Anxiety }\end{array}$} & \multicolumn{2}{|c|}{ Working } & \multicolumn{2}{|c|}{ Non-working } & \multicolumn{2}{|c|}{ Total } \\
\hline & f & \%age & $\mathbf{f}$ & \%age & $\mathbf{f}$ & \%age \\
\hline No Anxiety & 29 & 19 & 30 & 20 & 59 & 19.6 \\
\hline Mild & 87 & 58 & 100 & 67 & 187 & 62.2 \\
\hline Moderate & 28 & 19 & 18 & 12 & 47 & 15.6 \\
\hline Severe & 06 & 04 & 02 & 01 & 08 & 2.66 \\
\hline
\end{tabular}

Table.3 Distribution of working and non-working mothers on various levels of Coping Strategies

\begin{tabular}{|c|c|c|c|c|c|c|}
\hline \multirow{2}{*}{$\begin{array}{l}\text { Levels of Coping } \\
\text { strategy(CS) }\end{array}$} & \multicolumn{2}{|r|}{ Working } & \multicolumn{2}{|c|}{ Non-working } & \multicolumn{2}{|c|}{ Total } \\
\hline & $\mathbf{f}$ & \%age & $\mathbf{f}$ & \%age & f & \%age \\
\hline Low mindful CS & 6 & 4 & 19 & 12.6 & 25 & 8.33 \\
\hline $\begin{array}{l}\text { Moderate mindful } \\
\text { CS }\end{array}$ & 39 & 26 & 126 & 84 & 165 & 55 \\
\hline Highly mindful CS & 105 & 70 & 5 & 3.33 & 110 & 36.6 \\
\hline
\end{tabular}

Table 3 depicts the frequency and percentage distribution of working and non-working mothers on the basis of various levels of coping strategies. The results indicates that total respondents showed moderate mindful coping strategies $(55 \%)$ followed by high
(36.6\%) and least showed low mindful coping strategies that indicate that working and nonworking women are managing the lockdown and pandemic in a balanced approach and not letting the situation overpower them completely. The data also reveals that 
working women outnumbered $(70 \%)$ the nonworking women $(3.33 \%)$ with respect to following highly mindful coping strategies. As far as non-working mothers are concerned, the figures indicate that just $5 \%$ of them were following highly mindful CS and but majority (84\%) showed moderate CS. This indicates that working women are dealing with covid19 related anxiety and lockdown in a more mindful manner than their counterparts. The items related to copying strategies were based on utilization of extra time, indulgence in binge eating and drinking, screen time, hobby, physical activity, socialization etc. This proves that working women were following better regime during lockdown as compared to non-working women. Findings are in congruence with the study of Rathor (2015) who indicated that working women are more resilient than non-working and cope up better with stressful situations.

The findings of the study revealed that:

Covid related Anxiety among working mothers were higher than non-working mother, though the differences were insignificant.

Coping strategies to combat lockdown among working women were more mindful than nonworking women with significant statistical differences.
The study suggests that similar study after unlock should be conducted to see the pattern of anxiety and coping strategies among different population groups.

\section{References}

Cooper (Eds). Current trends in occupation stress. Newyork Weily (1981).

Iqubal, A., Nadeem, R., Fatima, N., (2004). Anxiety in non- working women with reference to their education family system and number of children, Journal of medical science, Pakistan, 20, 345-348.

Kamau, C.W. (1992). burnout, locus control and mental health of teachers in eastern province of Kenya. Unpublished Ph.D. thesis, Department of education, Punjab University. Comparative study of working and non-working married women effect of anxiety level on life satisfaction, Indian Journal of psychology and Mental Health .7(5):130-138.

Rathore R. (2015). Resilience: stress bouncer in working Indian women. J. Resh. 51

Shree R. (2016) Anxiety Between Working and Non-Working Women. Indian $J$ Resh. Vol. (5):8 Pp:253-54.

\section{How to cite this article:}

Prachi Bisht and Deepika Vig. 2020. Covid-19 Related Anxiety and Coping Strategies among Urban Working and Non-working Mothers in North India. Int.J.Curr.Microbiol.App.Sci. 9(07): 2075-2079. doi: https://doi.org/10.20546/ijcmas.2020.907.240 